\title{
Mercury deposits as incidental CT findings on a coronary calcium score
}

\section{Depósitos de mercurio como hallazgo tomográfico incidental en un índice de calcio coronario}

José J. Lozoya del Rosal*, Francisco J. Azar-Manzur, Christian Buelna-Cano, and Enrique Vallejo

Cardiovascular Center Department, Centro Médico ABC, Mexico City, Mexico

Forty seven-year-old male referred to our center for coronary artery calcium score to be determined. Relevant past history included a suicide attempt with elemental mercury intravenous injection. Non-contrasted tomographic images of the heart showed evidence of calcium on circumflex (11 Agatston units) and right coronary artery (28 Agatston units). Diffuse metal deposits were identified on exploratory images (Fig. 1). Metal deposits were also observed on the right ventricle and lung, both consistent with mercury (Fig. 2). Mercury poisoning is a rare event, generally associated with suicide attempts or accidental injections ${ }^{1}$. Mercury can cause acute or chronic toxicity, due to both embolic and chemical damage to the lungs, heart, kidney, liver and brain; chronic course can occur without clinical toxicity ${ }^{2}$.

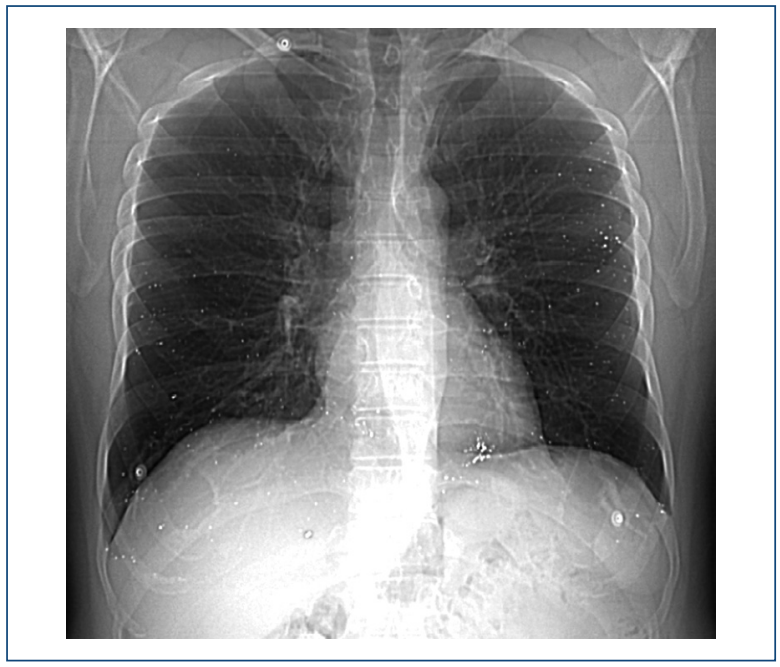

Figure 1. Images revealing metal deposits in the lung and heart.
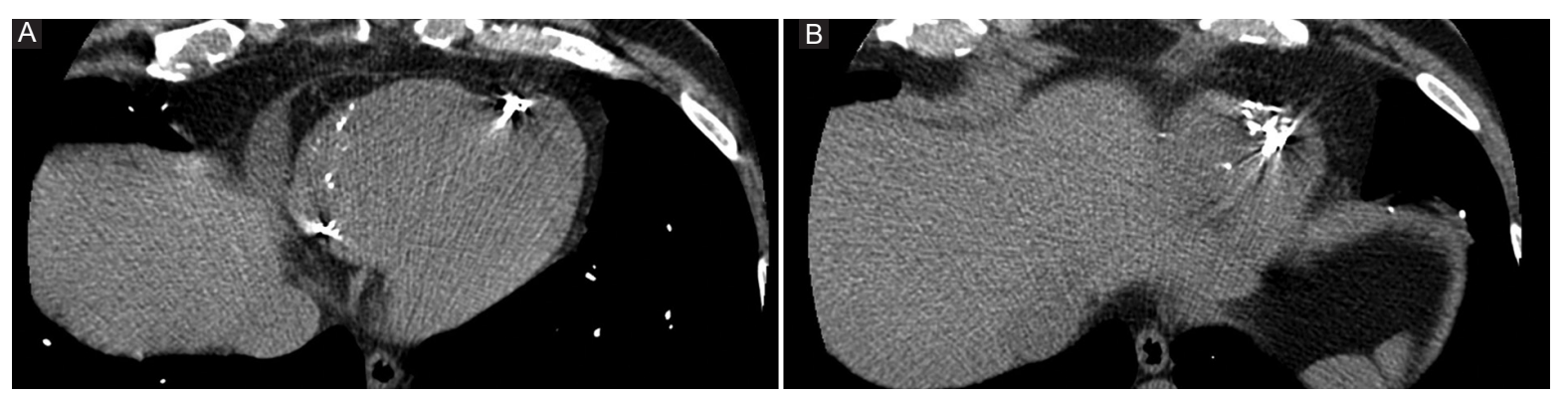

Figure 2. Non-contrasted tomographic images of the heart showing metal deposits on lateral wall (A) and right ventricular apex (B).

\section{Correspondence:}

*José J. Lozoya del Rosal.

E-mail: pepeloz@gmail.com

2604-7063/0 2020 lnstitut license (http://creativecommons.org/licenses/by-nc-nd/4.0/) DOI: 10.24875/ACME.M21000204
Available online: 19-07-2021 Arch Cardiol Mex (Eng). 2021;91(2):208-209 www.archivoscardiologia.com 


\section{Funding}

This research has not received any specific grant from public, commercial or non-profit sector agencies.

\section{Conflicts of interest}

None.

\section{Ethical disclosures}

Protection of human and animal subjects. The authors declare that no experiments have been conducted on humans or animals for this research.
Confidentiality of data. The authors declare that they have followed the protocols of their work centers on the publication of patient data.

Right to privacy and informed consent. The authors declare that no patient data appear in this article.

\section{References}

1. Bach AG, Restrepo CS, Abbas J, Villanueva A, Lorenzo Dus MJ, Schöpf R, et al. Imaging of nonthrombotic pulmonary embolism: biological materials, nonbiological materials, and foreign bodies. Eur J Radiol. 2013;82:e120-41.

2. Gutiérrez F, Leon L. Images in clinical medicine. Elemental mercury embolism to the lung. N Engl J Med. 2000;342:1791. 